\title{
High strain rate behaviour of polypropylene microfoams
}

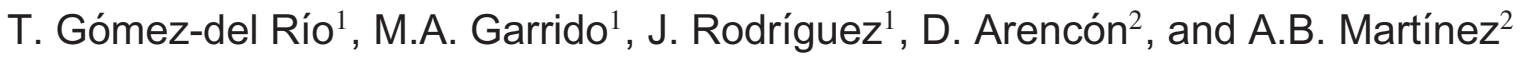 \\ ${ }^{1}$ Departamento de Tecnología Mecánica, ESCET, Universidad Rey Juan Carlos, C/Tulipán s/n 28933 Madrid, \\ Spain \\ 2 Centre Català del Plàstic, Dpt. Materials Science and Metallurgy, Universitat Politècnica de Catalunya - \\ BarcelonaTECH, C/Colom 114, 08222 Terrassa, Spain
}

\begin{abstract}
Microcellular materials such as polypropylene foams are often used in protective applications and passive safety for packaging (electronic components, aeronautical structures, food, etc.) or personal safety (helmets, knee-pads, etc.). In such applications the foams which are used are often designed to absorb the maximum energy and are generally subjected to severe loadings involving high strain rates.

The manufacture process to obtain polymeric microcellular foams is based on the polymer saturation with a supercritical gas, at high temperature and pressure. This method presents several advantages over the conventional injection moulding techniques which make it industrially feasible. However, the effect of processing conditions such as blowing agent, concentration and microfoaming time and/or temperature on the microstructure of the resulting microcellular polymer (density, cell size and geometry) is not yet set up.

The compressive mechanical behaviour of several microcellular polypropylene foams has been investigated over a wide range of strain rates $\left(0.001\right.$ to $\left.3000 \mathrm{~s}^{-1}\right)$ in order to show the effects of the processing parameters and strain rate on the mechanical properties. High strain rate tests were performed using a Split Hopkinson Pressure Bar apparatus (SHPB). Polypropylene and polyethylene-ethylene block copolymer foams of various densities were considered.
\end{abstract}

\section{Introduction}

Polymeric foams such as polypropylene foams are extensively used in energy absorption applications such as automotive crash safety systems, or personal safety (helmets, knee-pads, etc.). These materials may also be considered for higher rate applications such as trauma attenuation in advanced protective equipment against ballistic impacts and blast waves where the rates of deformation exceed $1000 \mathrm{~s}^{-1}$. Therefore in order to optimize the design of these structures, it is necessary to observe and understand the response of these materials under actual conditions of use.

The mechanical properties of cellular foams has been extensively investigated [1-5], but these materials exhibit densities of the order of 30 to $100 \mathrm{~kg} / \mathrm{m}^{3}$, i.e. more than 10 times lower than the density of the starting solid polymer. These foams have shown significant improvements in mechanical properties, such as strength-to-weight ratio, but it has been proved that a reduction in cell size can yield further improvement in properties. Thus was born the idea of creating microcellular foams, which are expected to have a reasonable strength for the intended applications [6].

Microcellular foams are usually defined as the foams having average cell sizes in the order of $10 \mu \mathrm{m}$ and cell densities in the order of $10^{9}$ to $10^{15}$ cells $/ \mathrm{cm}^{3}$ [7]. Also, microcellular foams have been of great interest to researchers in recent years because of their unique microstructure. Compared to unfoamed polymers and conventional foams, microcellular foams have some superior mechanical properties such as high impact strength $[8,9]$, high toughness [10], high stiffness-to-weight ratio [11], high fatigue life [12], and reduced material weight and cost. Therefore, microcellular foams have a great potential for applications such as packaging, insulation, automotive and aircraft industries, and structural components.
The mechanical properties of microcellular foams have been investigated by many researchers. Results have shown that unlike conventional foams, with typically large variations in properties, microcellular foams exhibit consistent and improved mechanical properties in systems such as PC, PET, ABS, and PVC [13]. For instance, the yield stress is modeled to vary linearly with the relative density of the foam $[14,15]$. It has been hypothesized that this occurs due to the reduction of cell size as well as the uniform and homogeneous cell structure of microcellular foams.

In the current study the compressive mechanical behaviour of several microcellular polypropylene-ethylene copolymer foams has been investigated over a wide range of strain rates $\left(0.001\right.$ to $\left.3000 \mathrm{~s}^{-1}\right)$ in order to show the effects of the processing parameters and strain rate on the mechanical properties. High strain rate tests were performed using a Split Hopkinson Pressure Bar apparatus (SHPB). Copolymers of different content of ethylene and various densities were considered.

\section{Experimental procedure}

\subsection{Material and specimens}

The materials studied were an isotactic polypropylene homopolymer (PP) and four ethylene-propylene block copolymers (BC1, BC5, BC7 and BC8). The PP homopolymer is characterized as having high isotacticity $(90 \%)$ and the copolymers a nominal ethylene content of $6.9,8.5,8.5$ and $11.2 \% \mathrm{wt}$, respectively.

Solid and foamed specimens of these five materials were prepared. The solid specimens were prepared by injection molding. The basic characteristics such as the 
Table 1. Basic properties of the solid copolymers under study.

\begin{tabular}{|l|c|r|r|r|r|}
\hline Sample & PP & BC1 & BC5 & BC7 & BC8 \\
\hline \% Ethylene (weight) & 0 & 6.9 & 8.5 & 8.5 & 11.2 \\
\hline \% Isotacticity & 90.0 & 89.3 & 85.4 & 84.2 & 81.0 \\
\hline Mn (kg/mol) & 126.0 & 160.5 & 65.7 & 56.1 & 60.8 \\
\hline
\end{tabular}

ethylene content, the molecular weight, $\mathrm{Mn}$, and the isotacticity are collected in table 1 .

\subsection{Foaming procedure}

The manufacturing process of the samples was injection moulding. A Victory 110 injection moulding machine (Engel $\mathrm{GmbH}$, Schwertberg, Austria) with a clamping force of $1100 \mathrm{kN}$ and a MTR-3 mould temperature controlling device (Industrial y Comercial Marse, S.L, Barcelona, Spain) was used for the production of the foamed parts. The injection moulding machine was equipped with a MuCell $®$ package supplied by the manufacturer. This package contains a special plasticizing unit with a $40 \mathrm{~mm}$ screw and maximum swept volume of $251 \mathrm{~cm}^{3}$, one supercritical fluid (SCF) series II $25 \mathrm{~mm}$ injection valve (Trexel Inc., Woburn, MA, USA). It also includes a SCF metering system that consists of a SCF SII delivery system (Trexel Inc., Woburn, MA, USA) and piping as well as instrumentation. $\mathrm{N}_{2}$ was the physical foaming agent employed.

A constant injection temperature profile was employed, being: $190,210,220,230,230^{\circ} \mathrm{C}$ from hopper to nozzle, using a injection speed of $130 \mathrm{~cm}^{3} / \mathrm{s}$. Mould temperature was set at $40^{\circ} \mathrm{C}$. $\mathrm{N}_{2}$ flow rate was varied to achieve the desired weight reduction. The cooling cycle was kept constant at $30 \mathrm{~s}$. Melt Plasticizing Pressure (MPP) was monitored to range at 200 bar. With these conditions, bars with circular section of nominal diameter $8 \mathrm{~mm}$ were injection moulded.

\subsection{Density}

A Mettler Toledo balance, with $\pm 0.001 \mathrm{mg}$, equipped with a density determination kit by means the buoyancy technique, was used to evaluate the change of density in the microcellular with different foaming grade. Five measurements were done for each specimen and three specimens were measured for each kind of material studied, determining the average value and their standard deviation (table 2).

\subsection{Quasi-static compression tests}

Quasi-static compression tests were performed using an electromechanical MTS universal testing machine with a load frame of $5 \mathrm{kN}$. Samples were tested at three different engineering strain rates ranging from 0.001 to $0.1 \mathrm{~s}^{-1}$. Right cylinders were machined with dimensions of $12 \mathrm{~mm}$ in thickness and $8 \mathrm{~mm}$ in diameter. To minimise interfacial friction all specimens were lubricated with CastrolTM LMX grease. At least three specimens were tested for each strain rate, allowing evaluation of the test reproducibility.
Table 2. Foaming grade and density of the samples obtained.

\begin{tabular}{|c|c|c|}
\hline \multirow{3}{*}{ Material } & $\begin{array}{c}\text { Percentage of } \\
\text { foaming } \mathbf{( \% )}\end{array}$ & $\begin{array}{c}\text { Density } \\
\left(\mathbf{g} / \mathbf{c m}^{3}\right)\end{array}$ \\
\hline \multirow{3}{*}{ PP } & 0 & 0.88066 \\
\cline { 2 - 3 } & 20 & 0.75084 \\
\hline \multirow{3}{*}{ BC1 } & 0 & 0.88483 \\
\cline { 2 - 3 } & 10 & 0.76353 \\
\cline { 2 - 3 } BC5 & 20 & 0.68184 \\
\cline { 2 - 3 } & 0 & 0.88342 \\
\cline { 2 - 3 } & 10 & 0.78612 \\
\hline \multirow{3}{*}{ BC7 } & 20 & 0.71657 \\
\cline { 2 - 3 } & 0 & 0.88547 \\
\cline { 2 - 3 } & 10 & 0.77309 \\
\hline \multirow{3}{*}{ BC8 } & 20 & 0.72122 \\
\cline { 2 - 3 } & 0 & 0.89161 \\
\cline { 2 - 3 } & 13 & 0.76767 \\
\hline
\end{tabular}

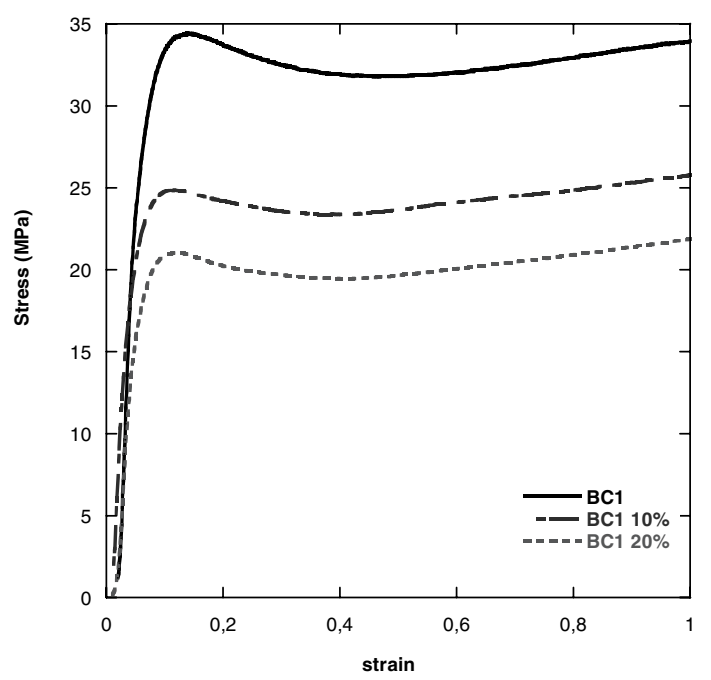

Fig. 1. Quasi-static compressive stress-strain curves of PB110 foams at about $0.01 \mathrm{~s}^{-1}$.

In order to measure the Poisson's ratio of each specimen tested, also a LIMESS video-extensometer was used. Raw data of longitudinal and transversal displacements were simultaneously recorded to extract Young's modulus and Poisson's ratio. From the loading history, the yield stress could be derived.

The true stress and true strain have been chosen to represent the foam behaviour for two principal reasons: first, concerning the strain, as the polymer undergoes a large range of deformation, the true strain definition of $\varepsilon=\operatorname{In}\left(1+\Delta l / l_{0}\right)$ is more appropriate; and secondly, the true stress for these materials $\sigma=F / S$ has been calculated with the variation of section (Poisson's ratio is closed to 0.5 in the post yielding region). The compression stress-strain curves of these different foams are shown in Fig. 1. Only results from one test of each foam density for a strain rate of $0.01 \mathrm{~s}^{-1}$ and one material is plotted and further analysis of all results will be presented in section 3 .

The mechanical behaviour of these foams at quasistatic compression is characterised by three phases: (1) a linear elastic behaviour ended in a maximum of stress that we consider to be the yield stress, (2) a non linear with 
negative slope part considered as a softening behaviour and (3) a final stage, which consists of foam densification.

\subsection{High strain rate compression tests}

Dynamic compression tests were conducted using a split Hopkinson pressure bar (SHPB). The SPHB device basically consists of an input bar, an output bar and a small cylindrical specimen located between them. Both bars are made of a high yield strength steel, $20 \mathrm{~mm}$ in diameter and lengths of 1.2 and $0.8 \mathrm{~m}$ for the input and output bars, respectively.

The projectile, a bar of approximately $0.3 \mathrm{~m}$ in length, is impelled against the input bar by means of an air gun. Due to the impact, an elastic compression pulse is generated in the input bar and travels along it up to the specimen, where is partially reflected and partially transmitted to the output bar. To measure the incident, reflected and transmitted pulses, strain gauges (VISHAY J2A-06-S047K-350) are attached to the bars. The strain gauge signals are recorded using a VISHAY 2200 conditioner connected to a TEKTRONIX TDS 420 A digital oscilloscope. In the input bar two gauge system was used in order to work with a longer incident wave. Both incident and output bar are made of steel. For the kind of materials tested, the impedance $(Z=\rho c)$ of the bars was approximately between 50 and 35 times higher than that of the microcellular foams used. Probably, the accuracy of the waves would be better if aluminium or polymeric bars had been use, but the impedance mismatch with steel bars is also acceptable [2].

The length to diameter ratio, $l / d$, of the specimens must be carefully chosen to ensure that stress equilibrium is achieved during the whole test. This equilibrium is achieved after an initial period which has to be as short as possible but it is dependant on the wave velocity within the specimen. Many researches agree that this stress equilibrium requires approximately four wave reverberations in the specimen. One solution is to reduce the thickness of the specimen which reduces the propagation time. So, the specimen height should not be as high as that of quasi-static tests. Due to the size of the bubbles and the microstructure of the microcellular foams, small specimens can enough as representative of the massive material. Finally, a thickness of $3 \mathrm{~mm}$ was chosen.

Some high strain rate size specimens ( $3 \mathrm{~mm}$ length) were tested in quasi-static conditions in order to verify there was no effect of the specimen height, nevertheless frictional effects were minimized using lubricants at both the bars or compression plates and specimen interfaces. Typical stress-strain curves for each foam density are plotted in Fig. 2.

\section{Results and discussion}

The yield stress (chosen as the first maximum of the true stress-true strain curve) is identified as the parameter in order to assess the effect of foam density and strain rate on the compression behaviour of the materials studied.

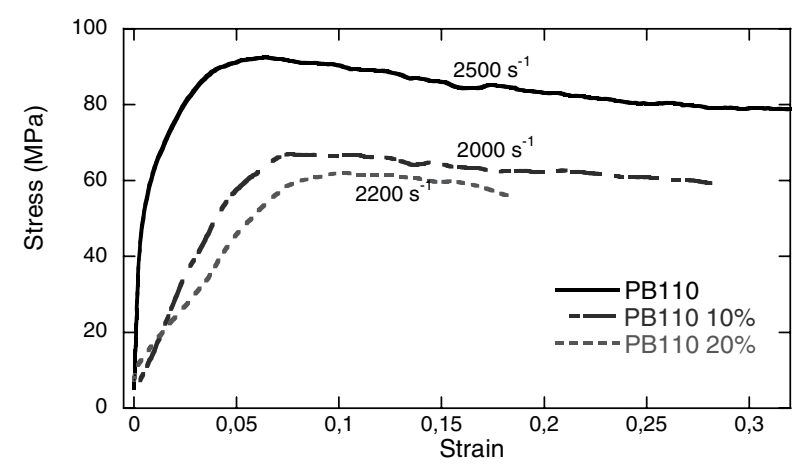

Fig. 2. Dynamic compressive stress-strain curves of PB110 foams at about $2200 \mathrm{~s}^{-1}$.

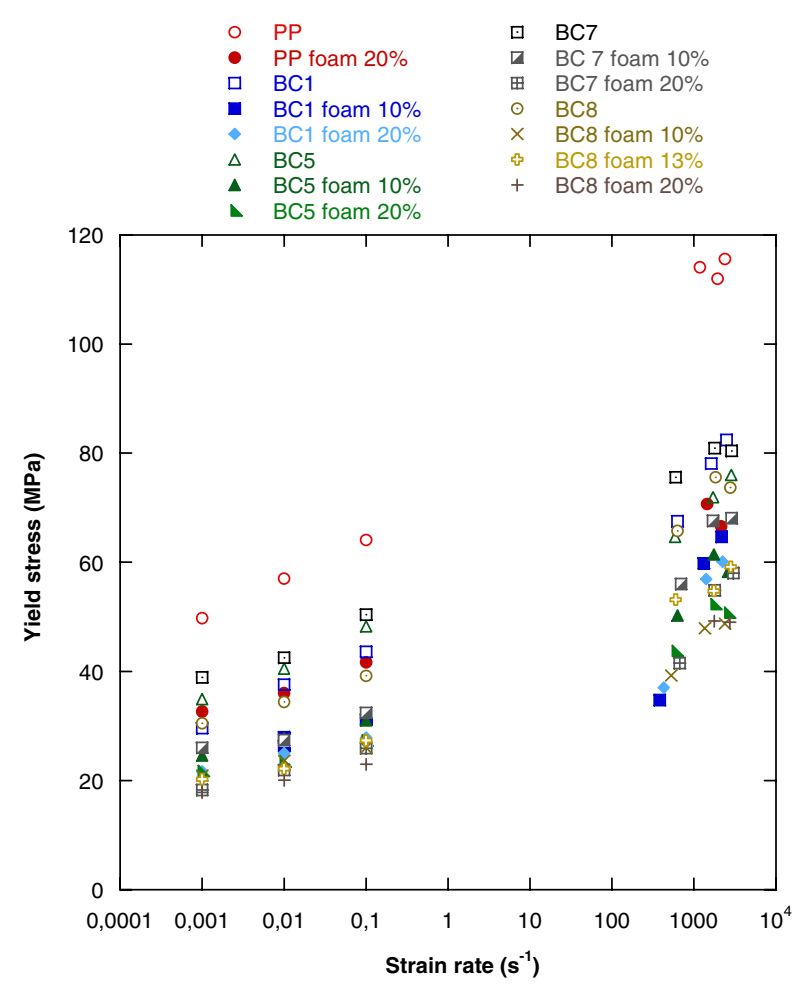

Fig. 3. Variation of the yield stress as a function of the density for all the strain rates (static and dynamic) and all the materials tested.

Yield stress vs. strain rate is plotted in Fig. 3 for all the materials tested. It can be appreciated that both the solid polymer and the foam behaviour shows an increase in strength with the strain rate. But this increment is not the same in all cases. A slighter increase is observed for the lowest density whereas denser foams seem to be more influenced. Two different zones can be appreciated depending on the strain rate regime. A quasi linear response for the quasi-static tests, and this slope increases with density showing an increase in the rate sensitivity. It has been suggested previously that, in order to describe the huge increment in yield stress at high strain rates, this behaviour can be better described, by a sinh function [16].

The yield stress $\sigma_{y}$ as a function of foam density is plotted in Fig. 4 for tests performed in an electromechanical universal machine and using the Hopkinson bar, for each kind of polymer: PP, BC1, BC5, BC7 and BC8. Experimental results can be compared with one analytical 

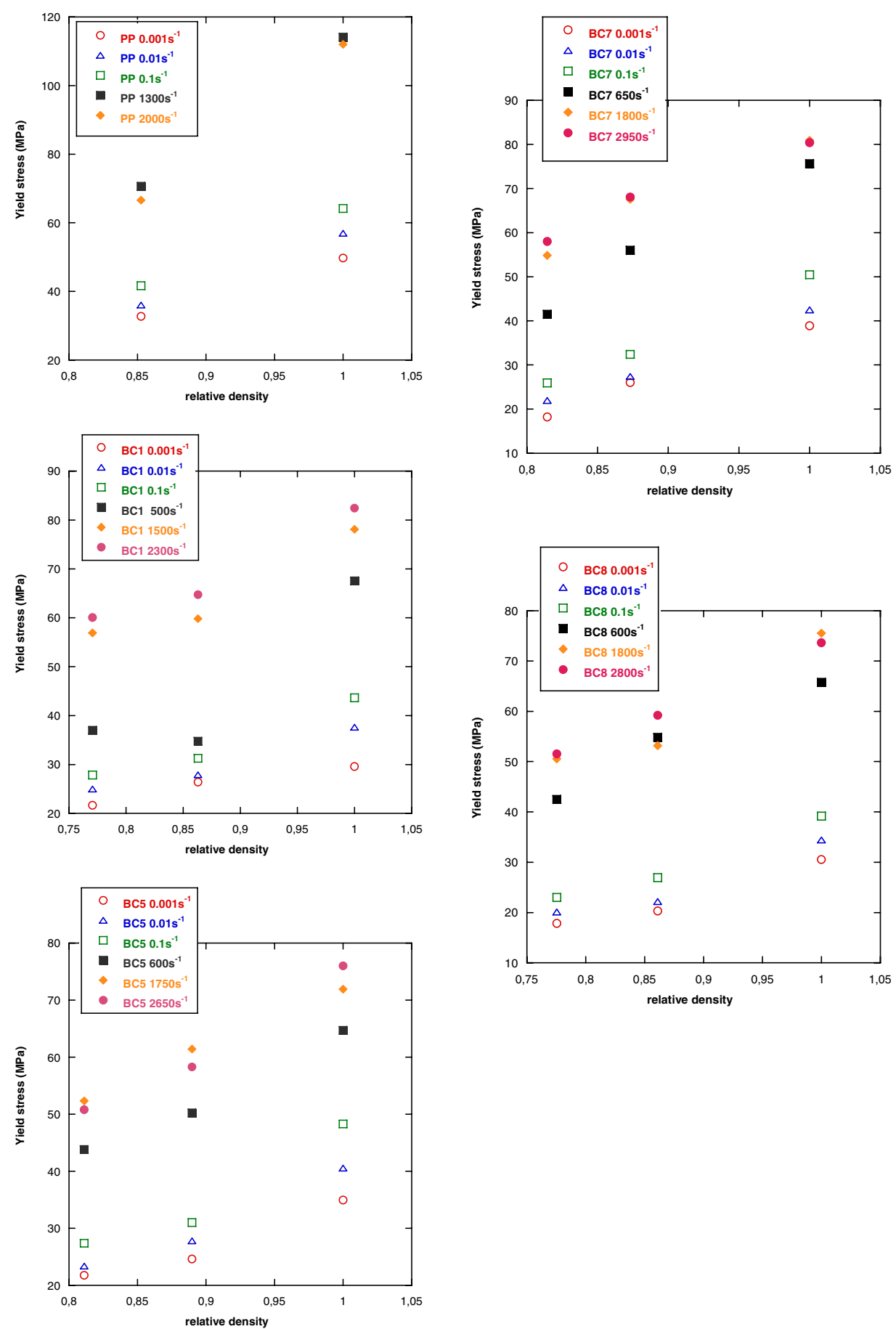

Fig. 4. Variation of yield stress as a function of density for all the test performed both at high and low strain rates, for the PP homopolymer and for each copolymer (BC1, BC5, BC7 and BC8).

model for close cell foams proposed by Gibson and Ashby.

$$
\frac{\sigma_{y}}{\sigma_{y}^{*}} \approx 0.3\left(\varphi \frac{\rho}{\rho^{*}}\right)^{3 / 2}+0.4(1-\varphi)\left(\frac{\rho}{\rho^{*}}\right)
$$

where $\sigma_{y}$ is the yield stress of the foam and $\sigma_{y}^{*}$ the collapse stress of the solid material.

Even though this model was developed for foams with relative densities below 0.8 , it has been previously used for microcellular foams with relative densities closed to $1[14,15]$. Nevertheless, it is said that for such kind of foams, also the rule of mixtures can be used.
This equation is based on a micromechanical model which considers the deformation mechanisms of the microcell structure under loading [2].

\section{Conclusions}

Yield stress of solid and microcellular foamed polypropylene and polypropylene-ethylene block copolymers has been measured in compression over a wide range of strain rates. From the experimental results the following 
conclusions can be ascertained:

- It has been shown that Hopkinson bar is an appropriate technique to determine the compressive yield stress of microcellular polypropylene foams at very high strain rates.

- Both solid and foamed polypropylenes under study show a significant increase of their compression yield stress with strain rates. This increase is accentuated at very high rates of strain, such as those characteristic of Hopkinson bar experiments.

- Under all conditions analyzed, the ethylene-propylene block copolymers, BC, presents lower values of compression yield stress than the polypropylene homopolymer, PP.

- As expected, the foam yield increases according to the density, but the strain rate sensitivity (increase in the yield stress) is less pronounced in foamed polymers compared to the solid ones.

\section{Acknowledgements}

Authors are indebted to Universidad Rey Juan Carlos, Comunidad de Madrid and Ministerio de Educación of Spain for their financial support through Projects CCG10-URJC/MAT-5413 and MAT2009-14294-C02-01.

\section{References}

1. L.J. Gibson, M.F. Ashby, Cellular solids. Structure and properties. Cambridge: Cambridge University Press; 1997.
2. R. Bouix, P. Viot, J.L. Lataillade. Int J Imp Eng 36, 329 (2009).

3. P. Viot, F. Beani, J-L. Lataillade. J Mat Sci 40, 5829 (2005).

4. J-J. Hwang, T. Adachi, T. Kuwabara, W. Araki. Mat Sci Eng A 487, 369 (2008)

5. D. Arencón, M. Antunes, A.B. Martínez, J.I. Velasco, Polymer Testing 31, 217 (2012).

6. D. Miller, V. Kumar, Polymer 52, 2910 (2011).

7. V. Kumar, M. VanderWel, J. Weller, K.A. Seeler. J Eng Mater Technol 116, 439 (1994).

8. L.M. Matuana, C.B. Park, J.J. Balatinecz. Cell Polym 17, 1 (1998).

9. D.I. Collias, D.G. Baird, R.J.M. Borggreve. Polymer 35, 3978 (1994).

10. D.F. Baldwin, N.P. Suh. ANTEC '92, SPE Tech Paper 38, 1503 (1992).

11. D. Klempner, K.C. Frisch. In: Handbook of polymeric foams and foam technology, Hanser Publishers, Munich (1991).

12. Seeler KA, Kumar V. J Reinf Plast Compos 12, 359 (1993).

13. Ch. Jo, J. Fu, H.E. Naguib, Polymer 46, 11896 (2005).

14. L.J. Gibson, M.F. Ashby. Proceedings of the Royal Society of London. Series A, Mathematical and Physical Sciences 382, 43 (1982).

15. L.J. Gibson, M.F. Ashby, G.S. Schajer, C.I. Robertson. Proceedings of the Royal Society of London. Series A, Mathematical and Physical Sciences 382, 25 (1982).

16. T. Gómez-del Río, J. Rodríguez. Europ Polym J 46, 1244 (2010). 